\author{
Military Technical College \\ Kobry El-Kobbah, \\ Cairo, Egypt
}

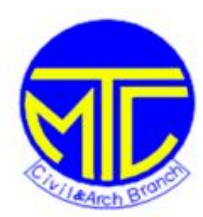

\title{
Effect of Tapering Ratio on the Elastic Stability of Thin-Walled Open Cross-Section Tapered Columns
}

\author{
Adel H. Salem *, Nabil Abdlmtaal **, \\ Mostafa M.Abd Al-whhab ${ }^{* *}$, and Zoulfikar Al-Yassin ${ }^{* * *}$
}

\begin{abstract}
:
The elastic buckling behavior of thin plates changing in width as well as hollow thin section tapered columns are studied using the finite element method. The buckling load is first defined for the case of simply supported trapezoidal plate subjected to uniform compressive stresses. The influence of tapering ratio, aspect ratio and flange width to average web depth ratio on the stability of thin -walled steel members is investigated. The results are compared to those of rectangular plates. The results are represented diagrammatically as function of the buckling coefficient with respect to the different mentioned ratios. The results show that, the buckling coefficient $(k)$ becomes larger as the tapering ratio decreases as well as the flange width to average web depth ratio also decreases.
\end{abstract}

Keywords:

Buckling Coefficient, Tapering Ratio, Aspect Ratio, Plates, Hollow Section Columns.

\section{Introduction}

Steel members with non-uniform cross-section are commonly used as columns in design of various structures. Depending on the mode of application, a plate element can be subjected to various in-plane forces (compression, bending, shear or a combination of these stresses).
* $\quad$ Ain Shams University
** $\quad$ Egyptian Armed Forces
*** M.T.C. 


\section{Proceedings of the $9^{\text {th }}$ ICCAE-9 Conference, May29-31, 2012}

Under certain circumstances, applied in -plane loading may cause buckling. The buckling of plates and columns plays an important role in structural safety and has been an important area of research for researchers. The stability of simply supported rectangular plates and hollow section columns, under the action of compressive forces uniformly distributed along the edges, was discussed by several authors, such as:

Timoshenko and Gere [1] studied the stability of rectangular plates under various conditions of support at the two edges parallel to the longitu dinal compressive forces using energy method.

Pope[2] presented analysis of buckling of a plate of constant thickness tapered symmetrically in planform and subjected to uniform compressive loading on the parallel ends.

Said Ahmed[3] studied the elastic critical buckling load of non-rectangular plates under different loading and boundary conditions using finite element analysis.

Persson[4] presented a new design charts for the critical buckling coefficient for flat plates under uniform compression with non -continuous boundary conditions.

Rasmussen, et. al. [5] presented numerical models for analyzing stainless steel simply supported plates in compression steel plates. To develop accurate finite element (F.E) models validated against the experimental plate t est results.

$\mathrm{Yu}$ and Schafer [6] presented an analytical method to calculate the buckling stress of a rectangular thin plate under nonuniform applied axial stresses using finite element analysis.

Salem, et. al. [7] presented a numerical investigations to st udy the strengths and behavior of steel rectangular plates simply supported on three sides, with remaining edge free (unstiffened), under the effect of different types of stress gradients using the finite element analysis.

Dabaon, et. al.[8] presented a numerical modeling to study the strength and behavior of stainless steel stiffened and unstiffened hollow -section columns under uniform axial loads. There are many other sources of information on elastic local buckling of plates $[9,10,11,12]$.

Considering only the first order terms in the governing equations

$$
\frac{\partial^{4} w}{\partial x^{4}}+2 \frac{\partial^{4} w}{\partial x^{2} \partial y^{2}}+\frac{\partial^{4} w}{\partial y^{4}}=\frac{12(1}{E t^{3}} \frac{\left.w^{s}\right)}{=}\left(-\sigma_{x} t \frac{\partial^{x} w}{\partial x^{2}}\right)
$$


where, $w$ denotes the deflection in the $\mathrm{z}$-direction of any point $(\mathrm{x}, \mathrm{y})$.

The elastic critical stress of rectangular simply supported plate under compression Fig.(1-a) can be expressed as:

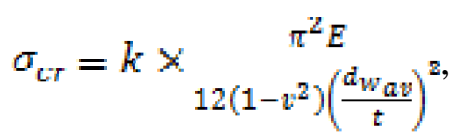

where $k$ is a dimensionless buckling coefficient of the plate and depends on the type of loading, edge support conditions, and the plate aspect ratio $L / d_{w_{a v}}$, while $E$ and $v$ are the Young's modulus and Poisson's ratio of the plate material, respectively. It was found that for the case of a solid rectangular plate, simply supported along its four edges and subjected to uniform compression at the two opposite short edges, the value of $k$ can be written as:

$$
k=\left(\frac{m d_{w_{a v}}}{L}+\frac{L}{m d_{w_{a v}}}\right)^{2}, \quad m=1,2,3, \ldots \ldots
$$

where $m$ corresponds to the number of half waves that occur in the plate's longitudinal direction at buckling, i.e. $m$ defines the buckling mode of the plate. The above equation was illustrated graphically in many textbooks and gives a minimum value of 4.0 for the buckling coefficient $k$, This minimum value occurs at $\left(L / d_{w \omega}\right)$ is an integer. For trapezoidal plates, $k$ also depends on the type of loading, edge support conditions, and the plate aspect ratio $L / d_{w_{a v}}$, and it's a function of the tapering ratio $r\left(r=d_{w_{1}} / d_{w_{2}}\right.$, see Fig.(1-b)), which can be obtained by finite element method.

\section{Problem definition}

A simply supported plate (column) subjected to uniform compressive stress in a Cartesian coordinate system is given in Fig. (1-a). The plate has length $(L)$, width $\left(d_{w_{4}}, d_{w_{n}}\right)$, thickness $(t)$ and tapering ratio $r=\left(d_{w_{1}} / d_{w_{2}}\right)$. In this study. The plate dimensions were $d_{w_{2}}=400 \mathrm{~mm}, \mathrm{t}=2.0 \mathrm{~mm}$, and the height of the plate was varied to obtain the required aspect ratio from 0.375 to 3.5 in order to investigate the effects of the aspect ratio $\left(L / d_{w_{a \varepsilon}}\right)$ on the buckling coefficient. For the thin wall structures simulated in this work, the height to thickness ratio of the plates had a range of 100 to 600. For hollow section columns under an axial compressive force with the top and bottom edges hinged or simply supported, the load is equally distributed on all of the 


\section{Proceedings of the $9^{\text {th }}$ ICCAE-9 Conference, May29-31, 2012}

plates. each plate has the individual critical load, and therefore each wall reaches instability simultaneously. The waves on adjacent walls are formed in such a way that the common edges do not buckle, both walls rotate the same amount and in the same direction about the common edge, and therefore the wall angle remains unchanged before and after buckling. This results in zero restraining moments at the common edges for the walls and the tube beha ves as four independent simply supported plates put together with common edges (see Fig.(3)). Walls of the square tube and tapered in web tube were modeled with a width $d_{w_{s}}=400 \mathrm{~mm}$, $d_{w_{1}}=d_{w_{2}} / r$, and a height of which was varied to obtain the required aspect ratio from 0.5 to 3.5 , similar to that of the model of the simply supported plate . Each wall and plate had a uniform thickness of $2.0 \mathrm{~mm}$. The four plates in Fig. $(3,4)$ were placed together in the form of a square tube. Each plate was independent of its adjacent plates.

\section{Finite element analysis procedure}

The commercial multipurpose finite element software program ANSYS (2011) was employed in this research. The general-purpose Elastic shell93 element is used to model the plate because it shows satisfactory performance in verification work previously described by [3] and [13]. the Elastic shell93 element has eight nodes possessing six degrees of freedom per node. The mesh density of the plate was chosen based on the size of the narrow edge of plate.

The default shell element size was selected $d_{w_{1}} / 20$ (Fig.(4)). The material of the plates was assumed to be homogeneous, isotropic and elastic. The material properties for Young's modulus $E=210 \mathrm{GPa}$ and Poisson's ratio $v=0.3$ were selected.

\section{Linear buckling analysis}

There are two types of buckling analyses: linear and nonlinear. The linear buckling analysis (or eigenvalue analysis) is performed in two steps. The first step is an elastic linear analysis which is performed to determine the internal reactions (initial stresses) in the structure due to externally applied loads. The second step is to determine eigenvalue based on the geometric stiffness matrix obtained from the linear analysis. ANSYS uses the first and second order terms of strain to generate the stiffness matrixes in the buckling analysis. The first term of strain yields the conventional stiffness matrix, $K_{\mathrm{C}}$, and the second term 
Proceedings of the $9^{\text {th }}$ ICCAE-9 Conference, May29-31, 2012

of strain for the initial stress stiffness matrix, $K_{r q}$. The initial stress stiffness matrix, $K_{\sigma}$, accounting for the effects of existing initial stress, is proportional to the stress level in the plate. The matrix equilibrium equation can be expressed as :

$$
\{F\}=\left(\left[K_{0}\right]+\left[K_{\sigma}\left(\lambda \sigma_{0}\right)\right]\right)\{D\}=\left(\left[K_{0}\right]+\lambda\left[K_{\sigma}\right]\{D\}\right)
$$

Initial stress $\sigma_{\mathrm{L}}$ is unknown at the beginning of the analysis. By applying a unit load to the plate, the initial stress reaches to the level of $\left(\lambda \sigma_{0}\right)$, where $\lambda$ is a scalar multiplier. $\{F\}$ and $\{D\}$ are the external load and the corresponding nodal displacement vector, respectively. At the buckling, the plate displacements increase with no increase in the external load. Mathematically, this can be defined by

$$
\left(\left[\mathrm{K}_{0}\right]+\lambda\left[\mathrm{K}_{\pi}\left(\sigma_{n}\right)\right]\{\mathrm{dD}\}\right)=0
$$

where $\{\mathrm{d} D\}$ is the incremental nodal displacement vector. The incremental displacement vector $\{\mathrm{d} D\}$ cannot be zero; therefore, a non-trivial solution of Eq. (4) is $\operatorname{Det} .\left(\left[K_{0}\right]+\lambda\left[K_{\sigma}\left(\sigma_{0}\right)\right]\right)=0$

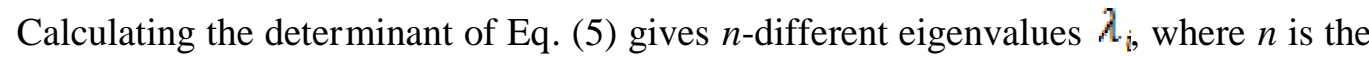
dimension of stiffness matrix. The lowest eigenvalue $\lambda_{1}$ corresponds to the critical load level $N o=\lambda_{1} * \sigma_{0} * t$, where buckling occurs. The associated eigenvectors represent the characteristic mode shapes of the buckled plate.

\section{Results and Discussion}

This section presents the results of the effect of aspect, tapering and flange width to web depth ratios on the buckling coefficient of plates(columns) subjected to uniform compressive load . the elastic buckling load ratio defined in Eq. (6) is used instead of the buckling coefficient

$k=\frac{N_{c r}}{\overline{N_{0}}}$

where $N_{c r}$ and $N_{0}$ is the elastic critical load of the non-uniform(trapezoidal) and rectangular plate, respectively. The elastic critical load of the rectangular plate is given as

$$
N_{0}=4 \times \frac{\pi^{2} E}{12\left(1-v^{2}\right)\left(\frac{a_{w a v}}{t}\right)^{2} \cdot t}
$$

In all figures, the variations of the buckling coefficient $(k)$ are plotted against the aspect ratio. Figure (5) shows, the influence of the plate aspect ratio $\left(L / d_{w_{a v}}\right)$ and the 


\section{Proceedings of the $9^{\text {th }}$ ICCAE-9 Conference, May29-31, 2012}

tapering ratio $(r)$ on the buckling coefficient of the plate. At the beginning, the values of $k$ decrease with the increase of the ratio $L / d_{w_{m m}}$, reaching the minimum value and starting from that value, $k$ increases with the increase of the ratio $L / d_{w_{a v}}$. With the increase of the ratio $r$, the values of $k$ increase and the minimum values move toward a slightly higher plate aspect ratios $L / d_{w_{a v}}$.

Figures (6and 7) show the variation of the buckling coefficient per wall of the different structures with the change of aspect ratio and flange w idth to web depth ratio. Figure (8) shows that, the buckling coefficient for column with $\mathrm{r}=1.0$ and $d_{f}$ $/ d_{w_{a 0}}=1.0$, is equal(nearly) to the critical load of a single simply supported rectangular plate. In general as showed in all figures, the buckling coefficient increases with decrease of tapering ratio and decrease of flange width to web depth ratio.

\section{Conclusions}

The results obtained lead to the following conclusions:

- The buckling coefficient for trapezoidal plates and also for tapere $\mathrm{d}$ columns is higher than the corresponding coefficient of rectangular plates and straight hollow section columns.

- The buckling coefficient of plated member increases with the decrease of the flange width to web depth ratio.

- As the aspect ratio of this series of plated members increase the plate buckles into more than one sine wave with a curved nodal line.

- It was assumed that the strength for square hollow section and with integer values of plate aspect ratio $\left(L / d_{w_{a v}}\right)$ can be determined by using the ac tual plate buckling coefficients than the classical value of $k=4.0$, while for rectangular hollow section columns, the buckling coefficient can be determined as:

$k=7-\left\lfloor 1.8 * w_{f} /\left(0.15+w_{f}\right)\right\rfloor-1.43 * w_{f}^{3}$

where $w_{f}=d_{f} / d_{w_{a v}}$ 


\section{Proceedings of the $9^{\text {th }}$ ICCAE-9 Conference, May29-31, 2012}

N.B.

An experimental investigation shall be also carried out on 9 tapered trapezoidal hollow section columns and this results will be compared with those obtained from F.E. method.

\section{References}

[1] Timoshenko and Gere " Theory of elastic stability ". New York: McGraw-Hill; (1961).

[2] Pope "The Buckling of Plates Tapered in Planform ". London;(1963).

[3] Said Ahmed "Stability of Non-Rectangular Steel Plates" Thesis presented to Ain Shams Univ. in Partial Fulfillment of the Requirements for the D egree of Master of Science in Engineering, Cairo; (1990).

[4] Persson " Plate Buckling Analysis Using Linear and Non -Linear FEM "Thesis presented to Youngstown State Univ. in Partial Fulfillment of the Requirements for the Degree of Master of Science in Engineering; (1996).

[5] Rasmussen, et. al. " Numerical Modeling of Stainless Steel Plates in Compression" Research Report No R813, Centre for Advanced Structural Engineering, Sydney; (2002).

[6] Yu and Schafer "Stress Gradient Effect on the Buckling of Thin Plates" Proceedings of the 17th International Specialty Conference on Cold-Formed Steel Structures, Orlando;(2004).

[7] Salem, et. al." Buckling and Post-Buckling of Unstiffened Plates under Stress Gradient" Proceedings of the 13th International conference on Structural and Geotechnical Engineering, Cairo (2009).

[8] Dabaon, et. al."Numerical Modeling for Stiffened and Unstiffened Stainless Steel Hollow Tubular Columns" 13th ICSGE,2009, Ain Shams University, Cairo, Egypt.

[9] Kiymaz "Stability and Strength Criteria for High Performance Steel Plates under Edge Compression "Journal of Istanbul Kultur Univ . pp.1-26 (2003)

[10] Wang, Chen and Xiang "Stability criteria for rectangular plates subjected to intermediate and end in-plane loads "Thin-Walled Structures ;42, 119-136 (2004)

[11] Braun " Stability of steel plates under combined loading" (2010).

[12] Maiorana, et. al. Elastic stability of plates with circular and rectangular holes subjected to axial compression and bending moment " Thin -Walled Structures 47 , 241-255 (2009).

[13] Korashy, et,al "New Proposed Slenderness Ratio for Thin -Walled Box-Section BeamColumns" $12^{\text {th }}$ ICSGE, Ain Shams Univ. Cairo-Egypt;(2007) 


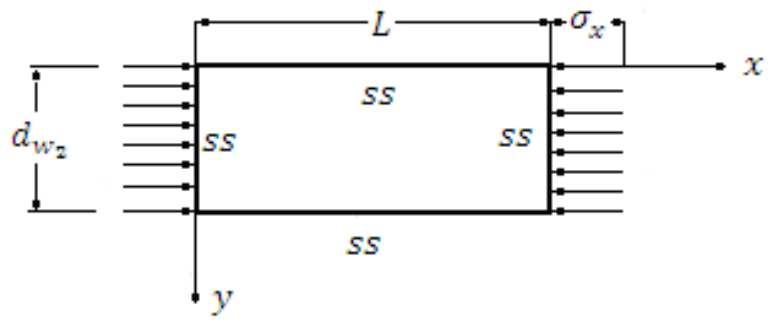

(a) Rectangular plate under compressive $\operatorname{Load}\left(d_{w_{1}}=d_{w_{2}}\right)$

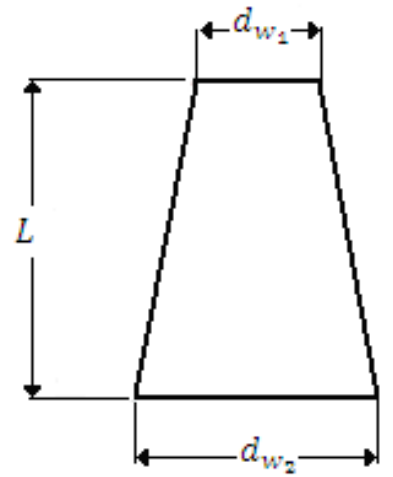

(b) Tapered plate $\left(d_{w_{1}} \neq d_{w_{2}}\right)$

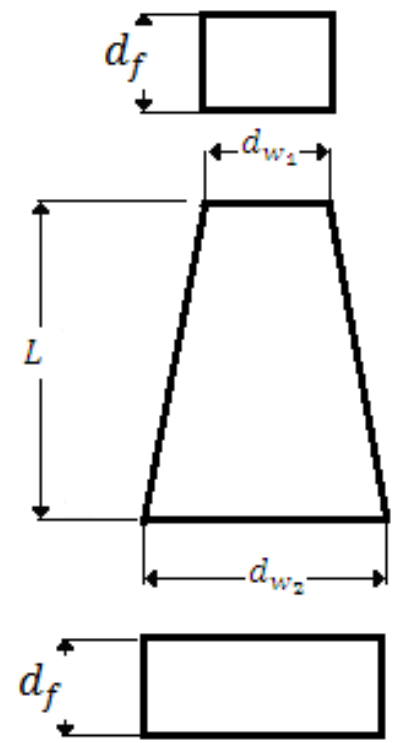

(c) Hollow thin section tapered columns

Fig.(1): Plate under compressive Stresses 


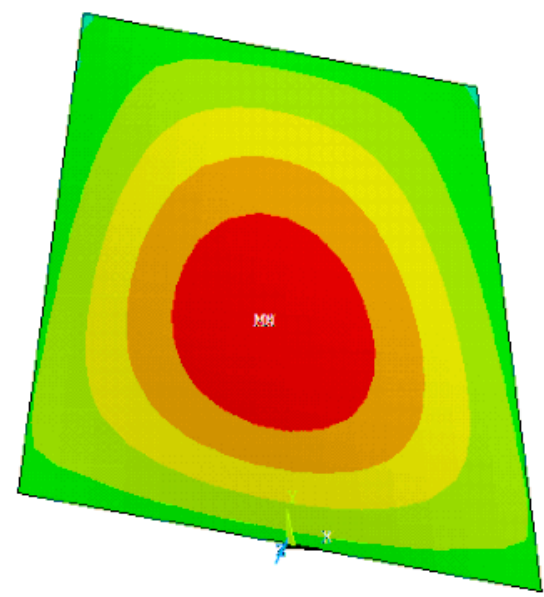

(a) Tapered plate $\left(L / d_{w_{a t}}=1.143 ; \mathrm{r}=0.75\right)$ $\mathrm{r}=0.75$ )

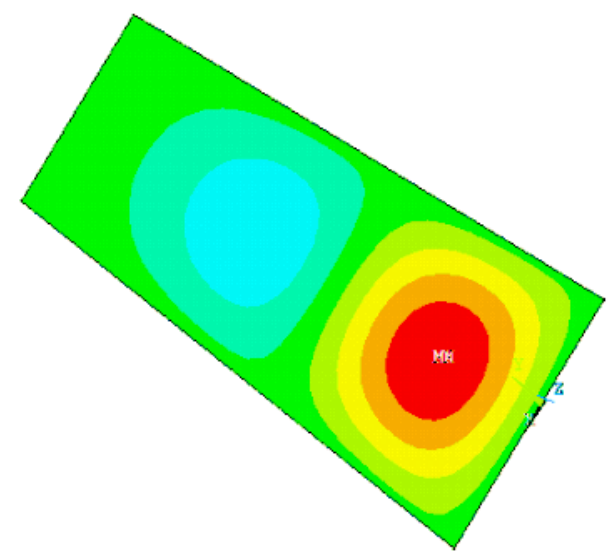

(b) Tapered plate $\left(L / d_{w_{a l}}=2.285\right.$;

Fig.(2): Deformed shape of trapezoidal plate
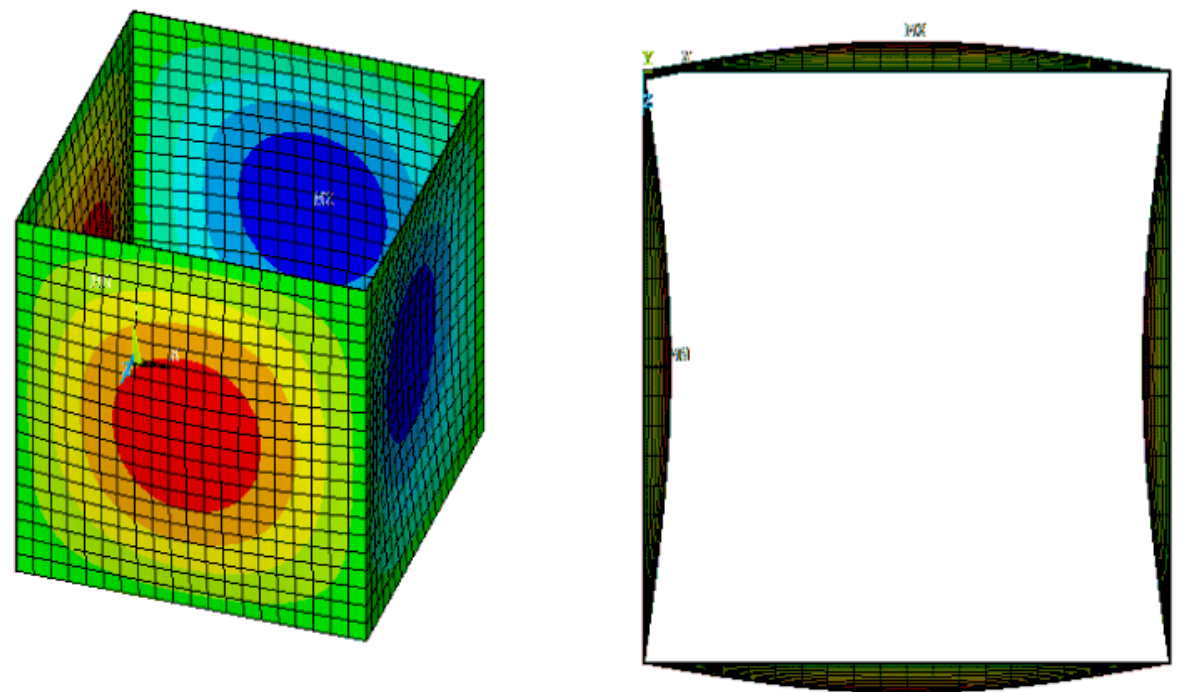

Fig.(3): Deformed shape of square hollow $\operatorname{section}\left(L / d_{w_{a s}}=1.0\right)$ 

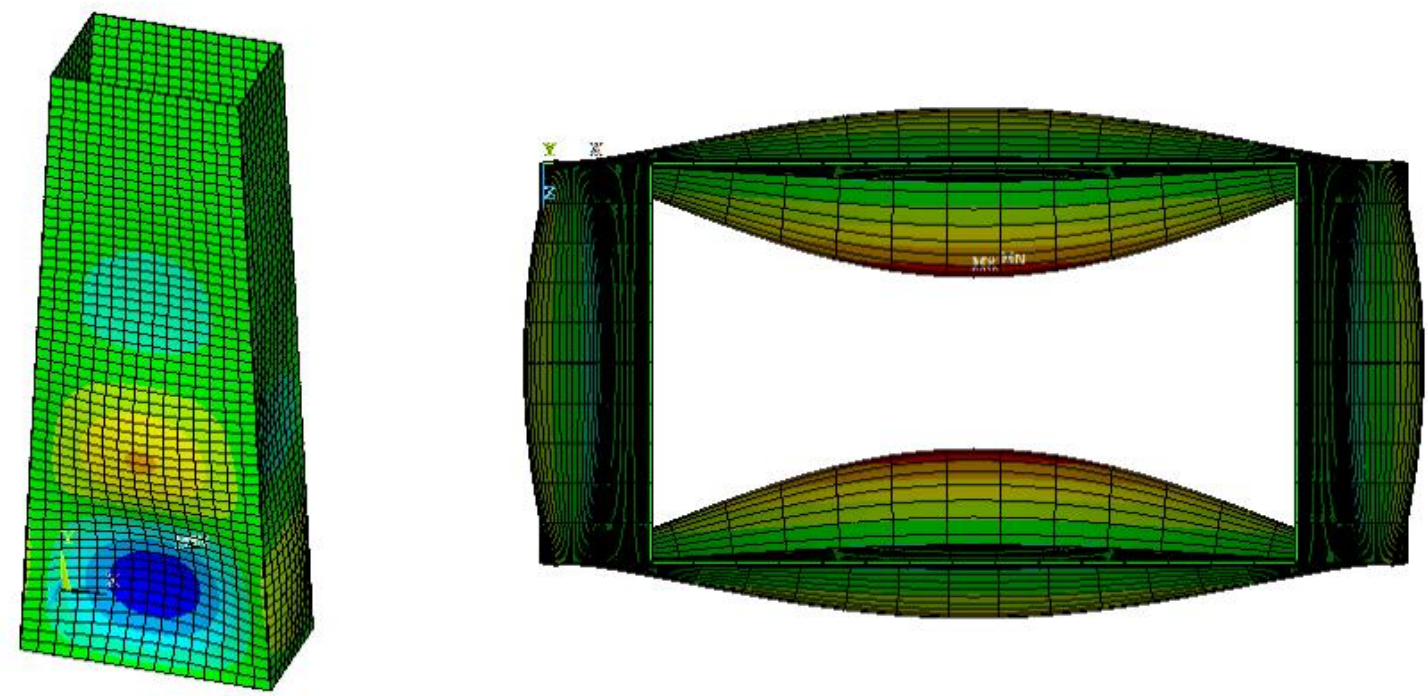

Fig.(4): Deformed shape of hollow section tapered column $\left(L / d_{w_{a v}}=3.2 ; d_{f} / d_{w_{a v}}=0.428 \mathrm{~L} ;\right.$ and $\left.\mathrm{r}=0.75\right)$

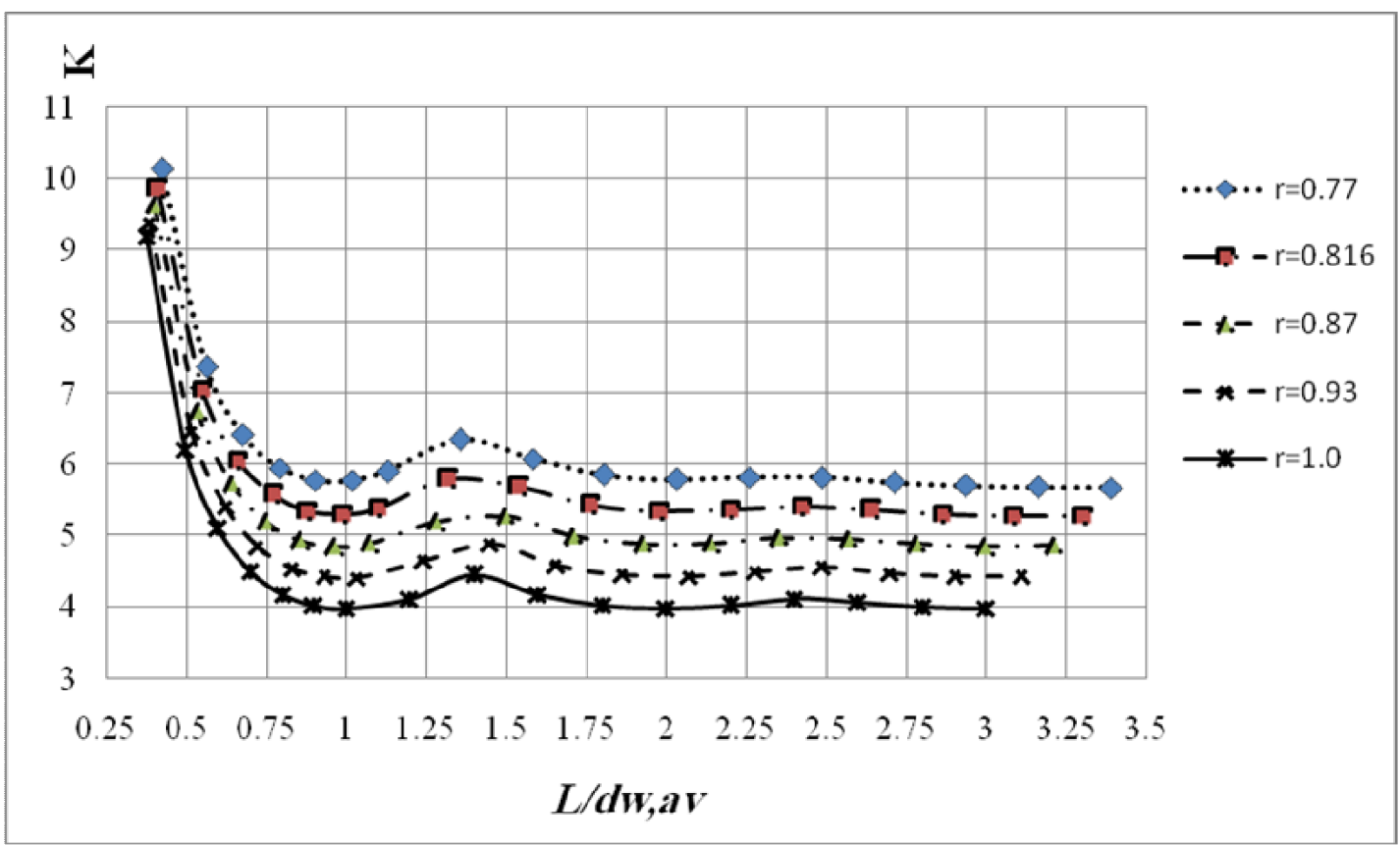

Fig.(5) : Effect of the plate aspect ratio $\left(L / d_{w_{a v}}\right)$ on the buckling coefficient of the plate for different Tapering Ratios 


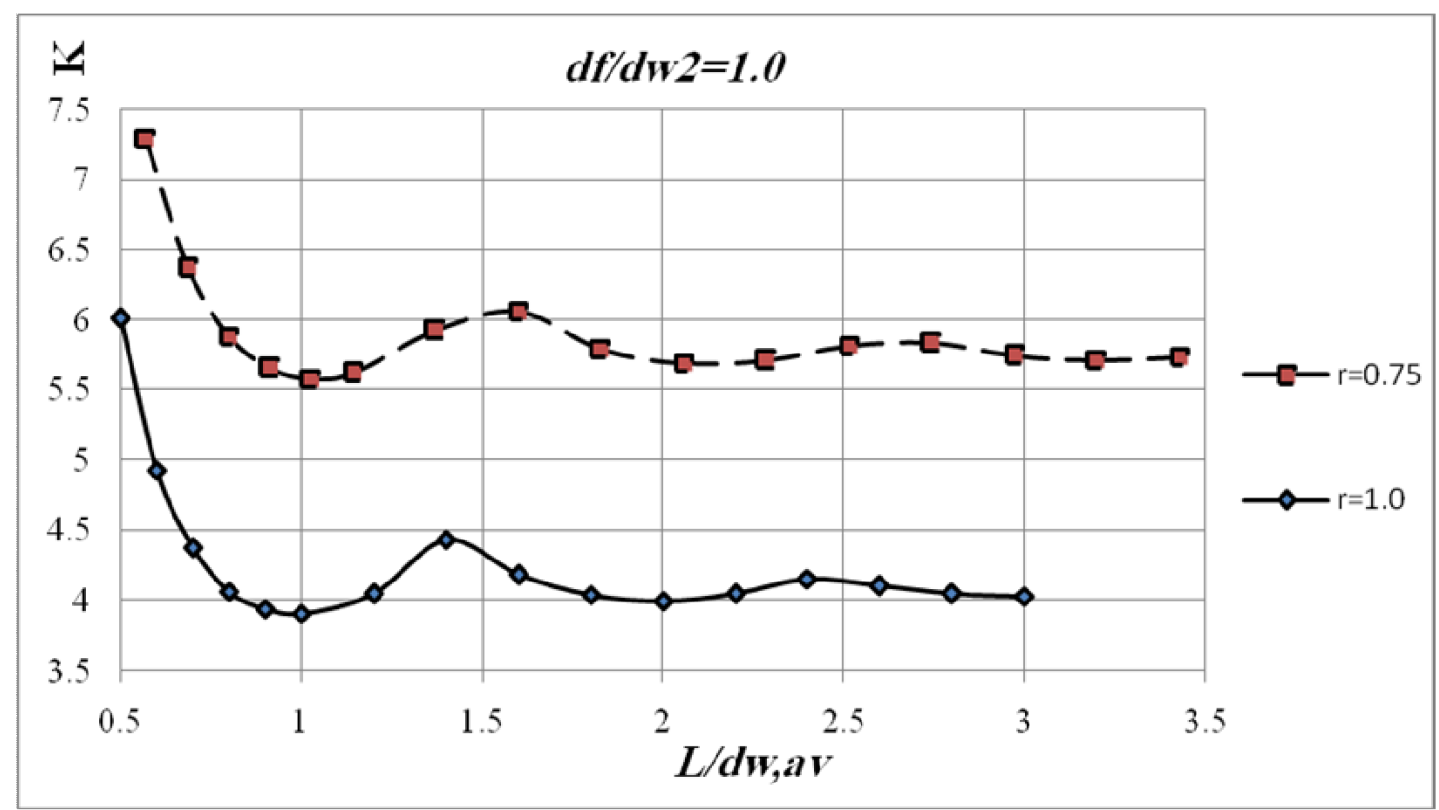

(a)

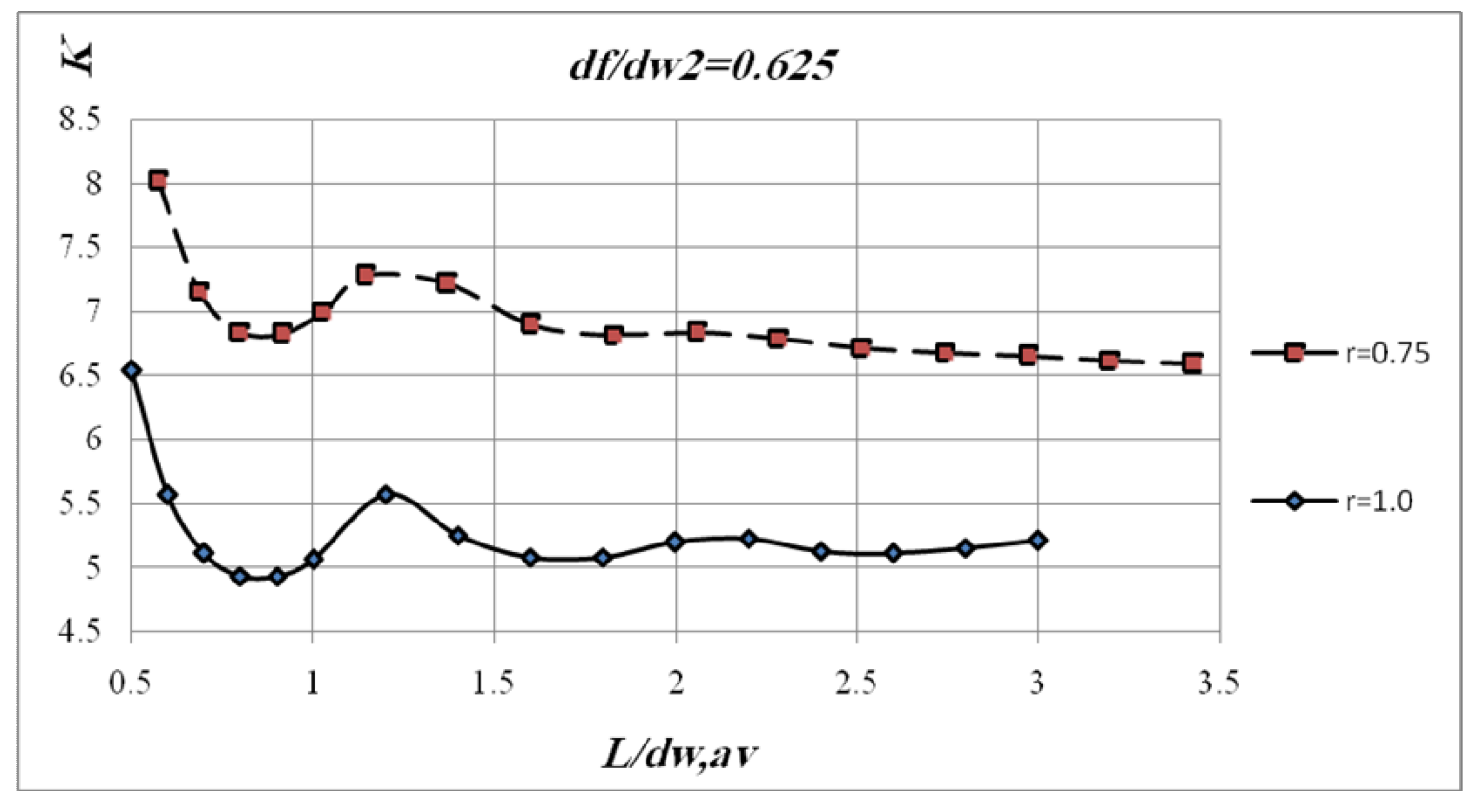

(b) 
Proceedings of the $9^{\text {th }}$ ICCAE-9 Conference, May29-31, 2012

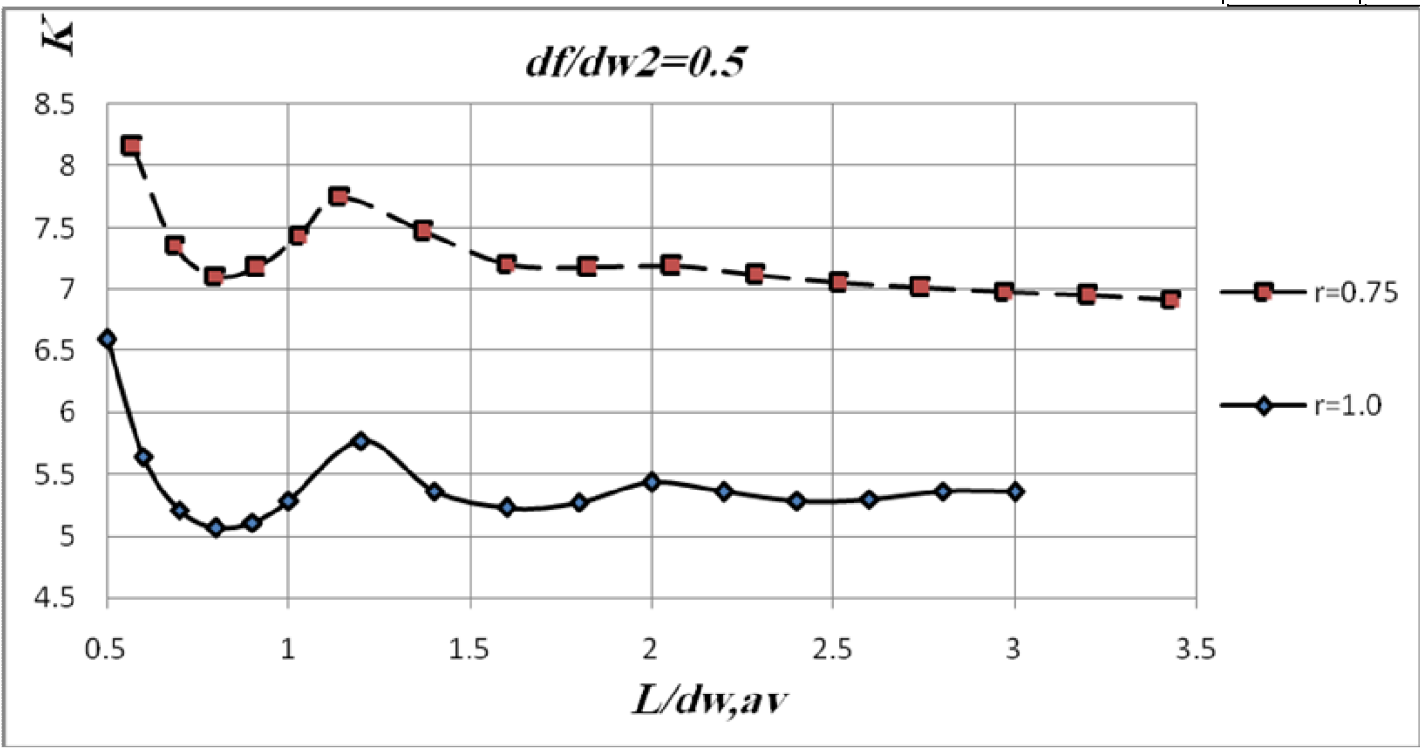

(c)

Fig.(6) : Effect of the plate aspect ratio $\left(L / d_{w_{a v}}\right)$ on the buckling coefficient of the HS Column for different Tapering Ratios

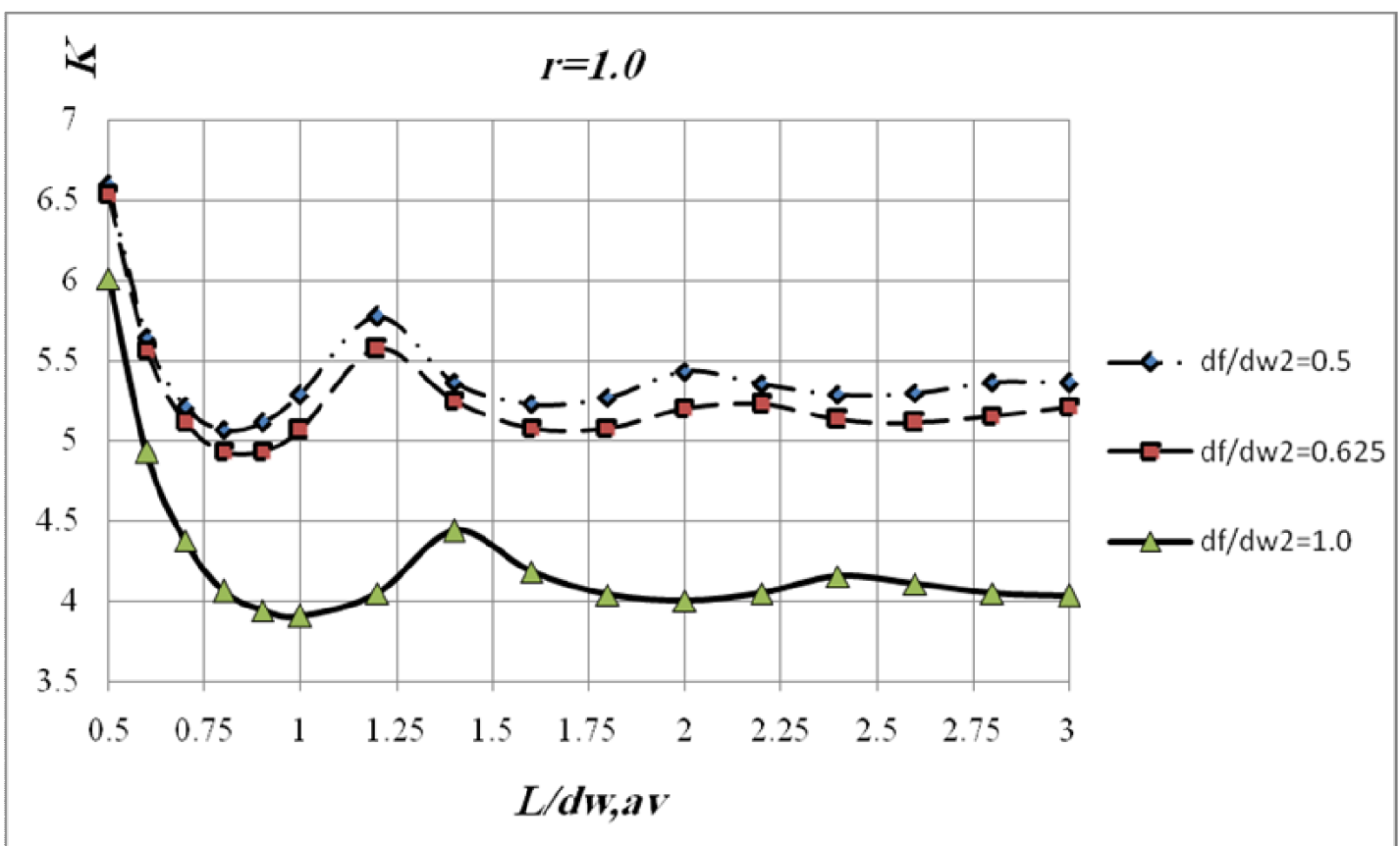

(a) 


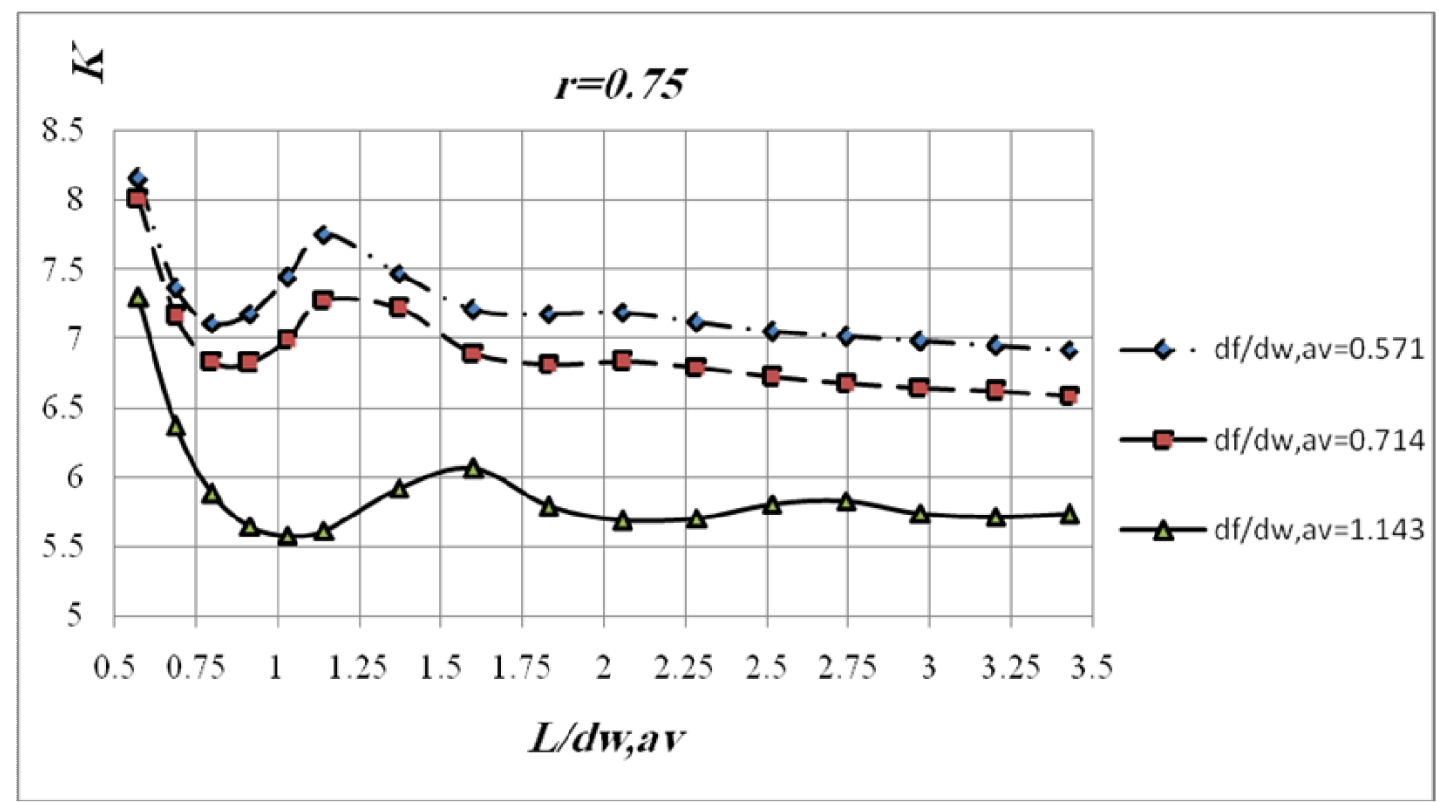

(b)

Fig.(7) : Effect of the plate aspect ratio $\left(L / d_{w_{a v}}\right)$ on the buckling coefficient of the HS Column for different Flange -Web Ratios

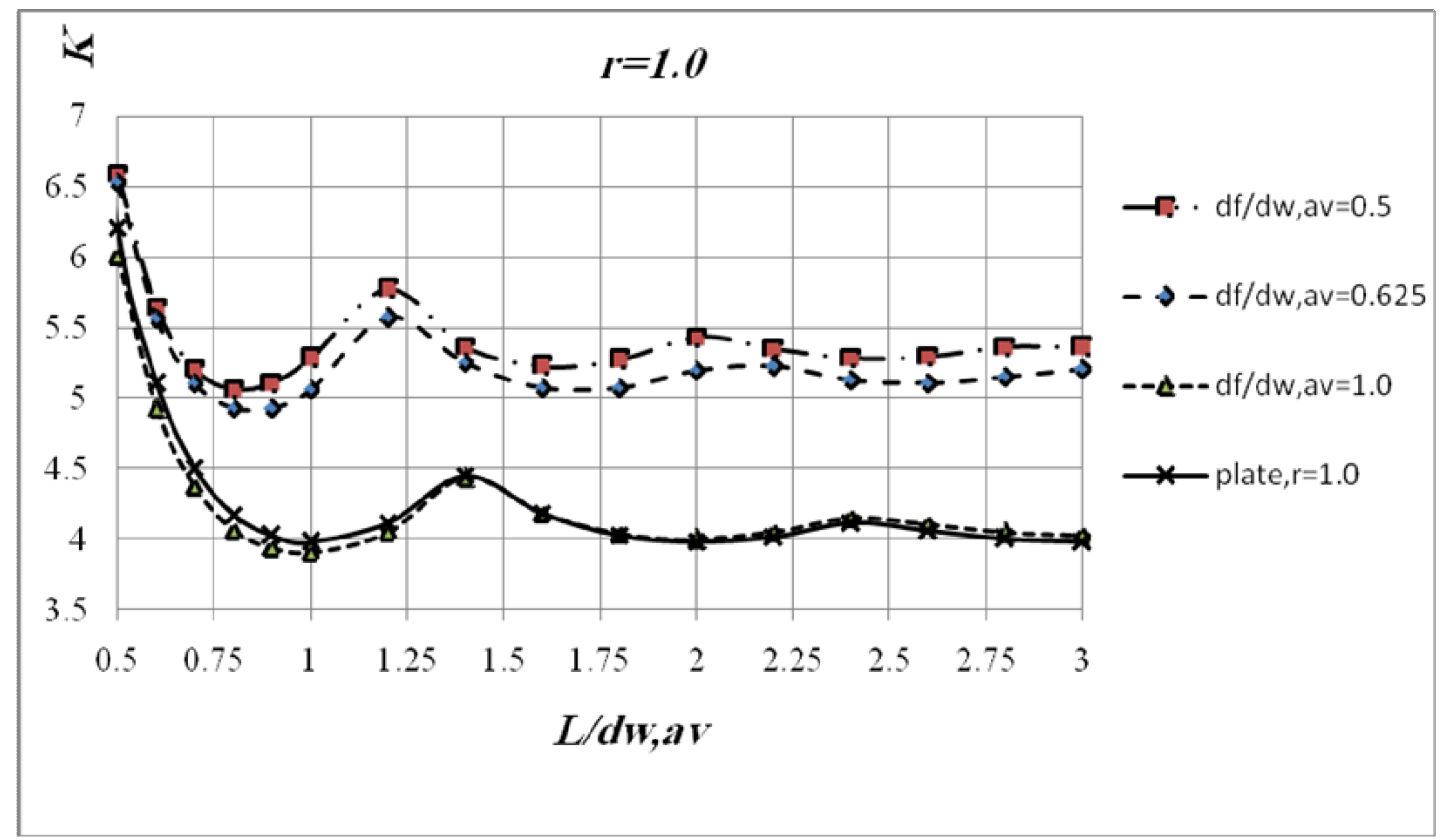

(a) 


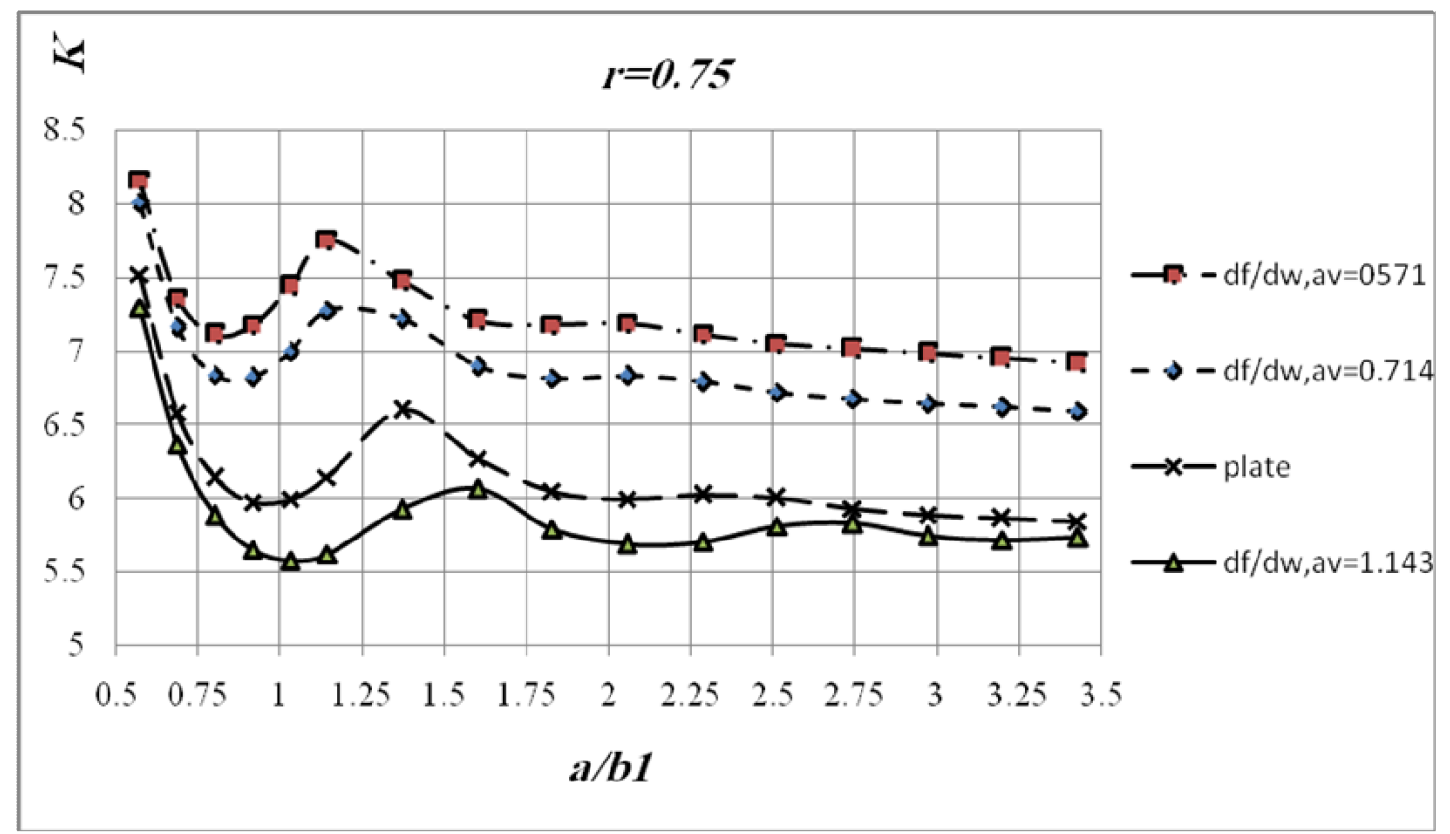

(b)

Fig.(8): Comparison between buckling coefficients of plates and columns

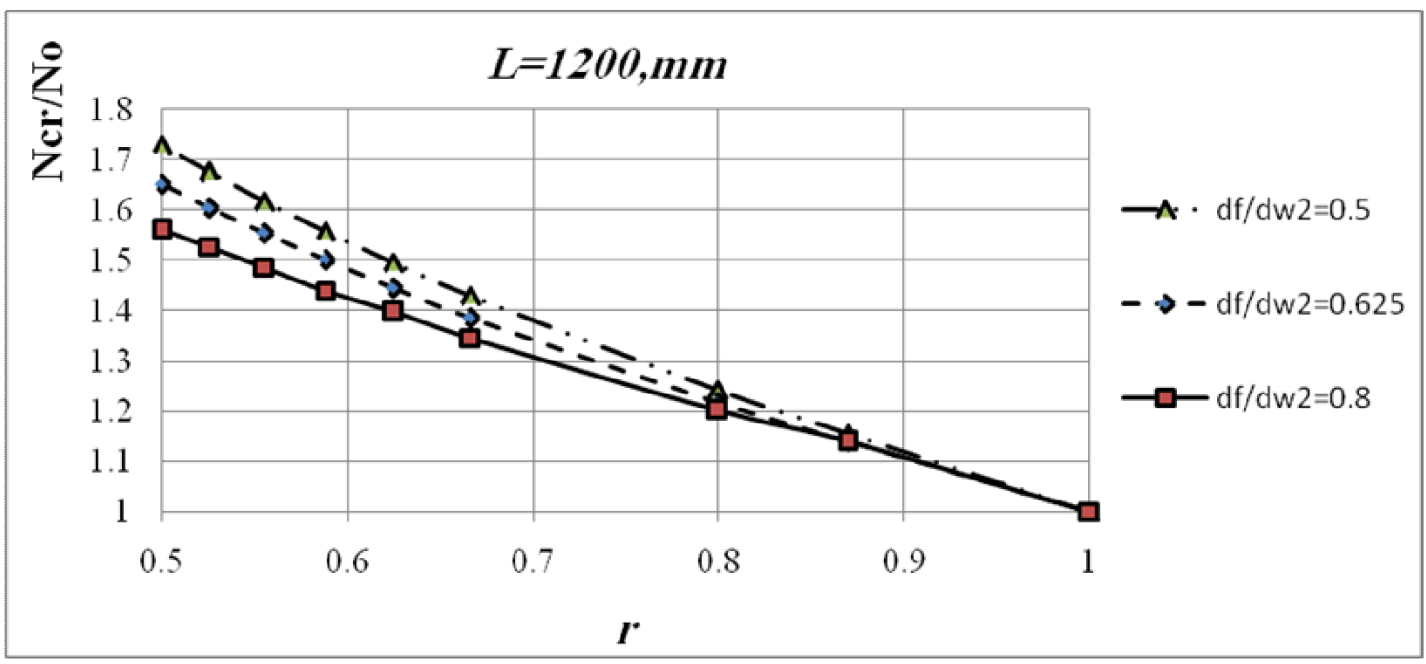

Fig.(9): Effect of tapered ratio on the buckling loads of columns for different Flange -Web Ratios 